\title{
Reliability and adequacy of current watertightness test standards used to evaluate the performance of façades
}

\author{
Maria Arce Recatala ${ }^{1, *}$, Soledad García Morales ${ }^{2}$, and Nathan Van den Bossche ${ }^{3}$ \\ ${ }^{1}$ Wintech Limited, Façade Engineering Consultancy, WV9 5HA Wolverhampton, United Kingdom. \\ ${ }^{2}$ Technical University of Madrid, Department of Construction and Technology in Architecture, 28040 \\ Madrid, Spain. \\ ${ }^{3}$ Ghent University, Department of Architecture and Urban Planning, 9000 Ghent, Belgium.
}

\begin{abstract}
Watertightness test standards are used to evaluate enclosure components in terms of water penetration resistance. Currently, there is a wide variety of watertightness tests in use for façades elements and wall systems. However, recent research has revealed many inconsistencies in the possibility of current test standards to reproduce real exposure conditions. As such, the main test parameters specified in watertightness test standards have been called into question. Nonetheless, these studies do not pay attention to the protocols and the technical specifications incorporated in the test standards. Neither to the influence that these aspects could have on the watertightness results. The present paper provides a general overview of current watertightness tests standards from around the world. Thereafter, a thorough comparison of the technical specifications incorporated in the protocols of the test standards has been carried out. Finally, an evaluation and discussion of some parameters suggested in the tests standards is undertaken based on the state of the art and laboratory experiments over diverse mock-ups.
\end{abstract}

\section{Overview of existing watertightness test standards}

The stages over a product's lifetime during which watertightness testing principally occurs are: (i) product design and development; (ii) recently installed products, and; (iii) during the useful service-life of the product [1]. In the early-life stages of the product, testing is completed to determine performance limits, to establish certification levels and to help ensure quality control. For this purpose, a mock-up is built and thereafter tested in laboratory conditions. Alternatively, over the product's mid- and later-life stages, testing clearly occurs on-site. Mid-life stages are considered those prior to the issuance of the building occupancy permit and no later than six months after the installation of the component [1]. Watertightness testing in mid-life stages is for quality assurance of the workmanship, whereas the testing is intended to reproduce actual leakage that has been observed during in-service conditions of the installed product in later-life stages.

* Corresponding author: m.arcer@alumnos.upm.es 


\subsection{Field test standards}

On-site watertightness test standards use three distinct approaches in which wind-driven rain and driving rain wind pressures are decoupled and independently treated, these being the hose, the spray bar and the cabinet.

The hose test generates a strong jet of water with a penetrating power far in excess of normal wind-driven rain exposure conditions [2]. Although the hose test does not reproduce the effect of wind pressure, it is assumed that the effect of kinetic energy can be simulated by the calibrated nozzle operating at a prescribed pressure at a specific distance from the test surface and moved at a specified sweep rate [3].

A spray bar is a long pipe fitted with holes or nozzles at regular intervals along its length. The spray bar will spray water at a set working pressure range, ensuring a constant film of water is sprayed onto the face of the façade test specimen and not forcing water into the joints, like in hose testing. Spray bar nozzles can be directed at specific joints but the standards usually recommend directing them at points above the joint, as it is a test for resistance against water penetration from water runoff.

Spray bar testing and hose testing may not simulate all of the effects of differential pressure and the ability of air moving through cracks or openings to transport water by percolation [3]. By contrast, site cabinet testing is supposed to reproduce better the extreme weather conditions and the action of both wind-driven rain and driving rain wind pressures. In site cabinet testing an air chamber is either mounted on the external or internal face of the façade test specimen, incorporating a means of pressurising or de-pressurising the cabinet, respectively. The basis of cabinet testing is to create a pressure difference on the façade test specimen, whilst spraying water onto the external face [2].

Chew [4] presented a review of the existing on-site watertightness tests standards for masonry walls. This overview of the currently available European and American field test standards is extended to every type of façade system and façade element in [5].

\subsection{Laboratory test standards}

Whereas field tests are useful to ascertain the performance of on-site workmanship, laboratory tests are useful to evaluate the design of the component (i.e. blocked drainage pathways and wrong detailing of joints). Laboratory tests are applied in the early stage of the product life to rate it with a performance class or performance level. While the performance class is generally prescribed as a direct function of peak wind pressure on the building, the performance level is obtained in respect of the ultimate limit state for resistance to wind loads of the product.

Laboratory test methods can be categorized into four distinct classes: static, cyclic, dynamic and wind tunnel testing. The first three test methodologies use a similar approach; wind and rain are decoupled and treated independently [6]. Whereas wind effects are reproduced by pressure differences generated by a fan, a water spray system placed in front of the specimen simulates the rain. The fourth method although is based on an integrated approach in a wind tunnel [40]. In it, water droplets are introduced into a high velocity air stream far enough from the test specimen. This allows the droplets to achieve the required velocity prior to impact and to simulate raindrops trajectories. Consequently, this is the most realistic effect of the actual weather conditions that may act over a wall or roof element.

Sahal and Lacasse [7] presented an overview of several laboratory water penetration test standards, which are classified according to the type of test procedure, applied test pressures, water spray rates and duration of tests. Based on the previous authors, a 
lengthened overview of the European, American, Asian and Australian laboratory test standards is given in [5].

\subsection{Test parameters}

Test conditions tend to eliminate all influencing parameters but three main variables for water-penetration testing: water application (named as water spray rate), air pressure difference between the interior and exterior surfaces of the test specimen [1] and duration of the pressure application. These variables are enforced and have a great impact on the water penetration performance of the test specimen as they directly affect some of the acting forces in support of water infiltration (kinetic energy, pressure differential and local air currents).

Water penetration test standards also incorporate some technical specifications, whose value ranges are typically suggested. These other related variables are: the conditioning of the laboratory (temperature of the water, surface tension of the water, relative humidity of the laboratory and temperature of the laboratory), the conditioning of the test specimen (amount of time a test specimen should be stored in the laboratory prior testing), the test equipment used to project water over the outermost surface of the test specimen (water spraying system, model of nozzle, method for applying the water load to the surface of the test specimen, working pressure range of the nozzle, spraying angle of the nozzle, distance to the outermost surface of the specimen, spray bar position, nozzles spacing and spray direction), the type of test procedure (static, cyclic, dynamic and wind tunnel testing) and the duration of the inspection for leakages.

Table 1 gives a comparison of the most typical value ranges provided for the main and related test parameters defined in American, Australian, Asian and European laboratory water penetration test standards.

Table 1. Overview of the most typical value ranges provided for the test parameters defined in American, Australian, Asian and European laboratory test standards used to assess the watertightness of facades and façade elements.

\begin{tabular}{|c|c|c|c|c|c|c|}
\hline \multicolumn{3}{|c|}{ Standards } & American & Australian & European & Asian \\
\hline \multirow{3}{*}{$\begin{array}{c}\text { Main } \\
\text { variables }\end{array}$} & \multicolumn{2}{|c|}{ Water flow rate } & $3.4 \mathrm{~L} / \mathrm{min}$ & $3 \mathrm{~L} / \mathrm{min}$ & $2 \mathrm{~L} / \mathrm{min}$ & $4 \mathrm{~L} / \mathrm{min}$ \\
\hline & \multicolumn{2}{|l|}{ Main Pressure } & $137 \mathrm{~Pa}$ & $300 \mathrm{~Pa}$ & $\begin{array}{c}50-100-150- \\
200-300- \\
450-600 \mathrm{~Pa}\end{array}$ & $\begin{array}{c}3 \text { steps to } \\
30 \% \text { of } \\
\text { d.w.p. }\end{array}$ \\
\hline & \multicolumn{2}{|c|}{ Pressure application per stage } & $10 / 15 \mathrm{~min}$ & $15 \mathrm{~min}$ & $5 / 10 \mathrm{~min}$ & $5 \mathrm{~min}$ \\
\hline \multirow{6}{*}{$\begin{array}{c}\text { Other } \\
\text { variables }\end{array}$} & \multirow{4}{*}{$\begin{array}{l}\text { Laboratory } \\
\text { conditioning }\end{array}$} & $\begin{array}{c}\text { Water } \\
\text { temperature }\end{array}$ & - & - & $4-30^{\circ} \mathrm{C}$ & - \\
\hline & & $\begin{array}{c}\text { Water surface } \\
\text { tension }\end{array}$ & - & - & $60 \times 10^{-3} \mathrm{~N} / \mathrm{m}$ & - \\
\hline & & $\begin{array}{l}\text { Relative } \\
\text { humidity }\end{array}$ & - & - & - & - \\
\hline & & Temperature & - & - & $23 \pm 5^{\circ} \mathrm{C}$ & - \\
\hline & \multicolumn{2}{|c|}{ Specimen conditioning } & - & - & $\begin{array}{c}4 \mathrm{~h} \text { at } 10- \\
30^{\circ} \mathrm{C} \& 25- \\
75 \%\end{array}$ & - \\
\hline & $\begin{array}{l}\text { Spraying } \\
\text { system }\end{array}$ & Device & $\begin{array}{l}\text { Matrix of } \\
\text { nozzles }\end{array}$ & $\begin{array}{c}\text { Matrix of } \\
\text { nozzles }\end{array}$ & $\begin{array}{l}\text { Matrix of } \\
\text { nozzles / } \\
\text { Spray bar }\end{array}$ & $\begin{array}{c}\text { Matrix of } \\
\text { nozzles }\end{array}$ \\
\hline
\end{tabular}




\begin{tabular}{|c|c|c|c|c|c|}
\hline & Height & NA & $\begin{array}{l}\text { within } \\
100 \mathrm{~mm} \\
\text { from the top } \\
\text { of specimen }\end{array}$ & $\begin{array}{c}\text { within } \\
75 \mathrm{~mm} \text { from } \\
\text { the top of } \\
\text { chamber }\end{array}$ & NA \\
\hline & $\begin{array}{c}\text { Distance to } \\
\text { the surface }(\mathrm{d})\end{array}$ & Uniform & $90 \mathrm{~cm}$ & $\begin{array}{l}25 \mathrm{~cm} \\
40 \mathrm{~cm}\end{array}$ & $40 \mathrm{~cm}$ \\
\hline & $\begin{array}{l}\text { Nozzles } \\
\text { spacing }\end{array}$ & Uniform & $\begin{array}{c}180 \mathrm{~cm} \\
\max .\end{array}$ & $\begin{array}{c}\text { If } \mathrm{d}=25,40 \\
\mathrm{~cm} \\
\text { If } \mathrm{d}=40,70 \\
\mathrm{~cm}\end{array}$ & \\
\hline & $\begin{array}{c}\text { Nozzle spray } \\
\text { direction }\end{array}$ & $0^{\circ}$ & - & $\begin{array}{c}0^{\circ} \\
24(+2)^{\circ}\end{array}$ & $0^{\circ}$ \\
\hline \multirow{3}{*}{ Nozzles } & $\begin{array}{l}\text { Wetting } \\
\text { pattern }\end{array}$ & - & Solid cone & Full cone & Full cone \\
\hline & $\begin{array}{c}\text { Spraying } \\
\text { angle }\end{array}$ & - & Wide angle & Wide angle & - \\
\hline & $\begin{array}{l}\text { Working } \\
\text { pressure }\end{array}$ & - & - & $200-300 \mathrm{kPa}$ & - \\
\hline
\end{tabular}

\section{Experimental method}

Recent research has primarily studied the relationship between the three main variables for water-penetration testing (refer to Table 1) and the real exposure conditions of the facades in the built environment. Nonetheless, it is still uncertain how can the performance class or performance level be affected by the value ranges provided to the other related test parameters. For this purpose, an experimental approach was adopted to study the impact on the results of water penetration of the following test parameters:

- Method for applying the water load to the test specimen surface: wind-driven rain or surface water flow.

- Distance of the spraying system to the outermost surface of the test specimen: $25 \mathrm{~cm}$ or $40 \mathrm{~cm}$.

\section{Results and discussion}

\subsection{Method for applying the water load to the test specimen surface}

American and Australian laboratory watertightness test standards typically suggest a matrix of nozzles to project water over the test specimen surface, refer to Table 1. However, some European test standards (e.g. EN 12865 [8], NT BUILD 116 [9], NT BUILD 421 [10] and FprEN 15601 [11]) make a distinction in the method for applying the water to the outermost surface of the test specimen, being these:

(i) Surface water flow, in which water flows down the vertical face of the test specimen by gravity. In this case, a horizontal row of nozzles spraying evenly above the top of the test specimen is proposed (e.g. EN 1027 [12]).

(ii) Wind-driven rain, in which it is intended to deliver water droplets over the surface of the test specimen with a certain kinetic energy load. Accordingly, a matrix of uniformly spaced spray nozzles is suggested (e.g. EN 12865 [8]).

Lacasse et al. [13] acknowledged these methods as (i) the cascade mode and (ii) the full spray configuration, respectively. The full-spray configuration results in a water load increase in proportion to the wall height due to migration downward of water along the face of the test specimen. Alternatively, water applied in a cascade mode prevents that non- 
absorptive test specimens are exposed to cumulative water loads at the lower portion of the test specimen. The water load on non-absorptive test specimens is independent of vertical location of the spray bar in the cascade mode [13].

Nine water penetration tests were conducted over two full-scale mock-ups with nonabsorptive claddings to study the impact of each method on the water ingress within the pressure-equalized façade systems. The first mock-up had one open vertical joint and five open horizontal joints. Alternatively, the second mock-up comprised one open horizontal joint and five open vertical joints. A joint profile blocked the opening of the horizontal joint in the second mock-up. A row of evenly spaced nozzles was used to deposit water at a rate of $2 \mathrm{~L} / \mathrm{min}$ per $\mathrm{m}^{2}$. The surface water flow and the wind-driven rain effect were simulated by means of the placement of the row of nozzles in relation to the horizontal joint.

During the tests, it was measured the water infiltrated into the cavity and the water reaching the back wall of the façade specimens. The average results obtained are summarized in Table 2. Note that the percentages presented have been determined from the total amount of water sprayed onto the surface of the test specimen.

Table 2. Average water infiltration percentages obtained for each façade mock-up in relation to the method for applying the water load to the surface of the test specimen.

\begin{tabular}{|c|c|c|c|c|}
\hline & \multicolumn{2}{|c|}{ Surface water flow } & \multicolumn{2}{c|}{ Wind-driven rain } \\
\hline & $\begin{array}{c}\text { Water } \\
\text { infiltrated into } \\
\text { the cavity (\%) }\end{array}$ & $\begin{array}{c}\text { Water } \\
\text { reaching back } \\
\text { wall (\%) }\end{array}$ & $\begin{array}{c}\text { Water } \\
\text { infiltrated into } \\
\text { the cavity (\%) }\end{array}$ & $\begin{array}{c}\text { Water } \\
\text { reaching back } \\
\text { wall (\%) }\end{array}$ \\
\hline Mock-up 01 & $22.05 \pm 0.42$ & $0.09 \pm 0.01$ & $21.32 \pm 0.31$ & $0.29 \pm 0.10$ \\
\hline Mock-up 02 & $1.84 \pm 0.10$ & - & $1.47 \pm 0.09$ & - \\
\hline
\end{tabular}

Very similar percentages of water infiltration into the cavity were obtained in mock-up 01 regardless of the method used for applying the water load. However, an increase of $0.20 \%$ in the water entry rates onto the back wall was observed when the test specimen was sprayed with wind-driven rain. On the other side, a decrease of $0.37 \%$ in the amount of water infiltrated into the cavity was recorded in mock-up 02 when the façade specimen was sprayed with wind-driven rain. This reduction in the water infiltration rate into the cavity might be due to the effect of blocking the opening of the horizontal joint. The wind-driven rain approach provides water droplets with more kinetic energy load. Consequently, a greater amount of water droplets can splash away from the profile at the horizontal joint not entering into the cavity. These results suggest that blocked horizontal joints are more sensitive to runoff water than to wind-driven rain and wind driven rain causes higher water entry rates onto the back wall in both open vertical and horizontal joints.

\subsection{Distance of the spraying system to the outermost surface of the test specimen}

European watertightness test standards typically suggest a distance of the spraying system to the exterior surface of the test specimen of either $25 \mathrm{~cm}$ or $40 \mathrm{~cm}$; refer to Table 1 . Research by Hoigard and Kudder [14] shown that as the nozzle distance from the test surface decreases, the water pressure impinging on the test surface increases. By consequence, the water droplets acquire more kinetic energy load and are able to reach longer infiltration distances. To evaluate to what extend the infiltration rates are affected by the distance of the spraying system to the outermost surface of the test specimen, we conducted four watertightness tests over the mock-up with one open horizontal joint and 
five open vertical joints. A joint profile blocked the opening of the horizontal joint. The façade specimen was subjected to surface water flow at a spray rate of $2 \mathrm{~L} / \mathrm{min}$ per $\mathrm{m}^{2}$. This surface water flow was generated by a bar of nozzles evenly spaced and placed above the horizontal joint. The distance of the nozzles to the exterior surface of the test specimen was varied from $25 \mathrm{~cm}$ to $40 \mathrm{~cm}$ in every other test.

An average rate of $7.69 \pm 0.82 \%$ of the sprayed water was found to be infiltrated into the cavity through vertical joints for a distance of $25 \mathrm{~cm}$ of the spraying system to the exterior surface of the test specimen. This percentage increased to an average rate of $9.09 \pm 1.08 \%$ for the distance of $40 \mathrm{~cm}$. Regarding the infiltration rates through horizontal joints, it was obtained that $1.88 \pm 0.09 \%$ of the sprayed water infiltrated into the air cavity through horizontal joints for the distance of $25 \mathrm{~cm}$. Alternatively, an average rate of $1.83 \pm 0.27 \%$ was obtained for the distance of $40 \mathrm{~cm}$.

Very similar infiltration rates through horizontal joints were obtained for the distances of $25 \mathrm{~cm}$ and $40 \mathrm{~cm}$. These results suggest that the distance of the spraying system to the exterior surface of the test specimen has not an impact on the water entry rates through horizontal joints, when the opening is blocked and the surface of the specimen is wetted via surface water flow. In contrast, increasing the distance of the spraying system to the exterior surface of the test specimen yielded to higher infiltration rates through vertical joints. It appears that open joints are sensitive to the splash and bounce effect created when the distance of the spraying system to the surface of the test specimen is smaller and the water pressure impinging on the test surface increases.

\section{Conclusions}

The comparison of the different watertightness test standards and the subsequent critical evaluation of some of the related test parameters has called into question many of the technical specifications incorporated in the standards.

Being the first concern observed, the variance in the value ranges provided for the test parameters and technical specifications. These inconsistencies suggest that there is not a common criterion on the way of simulating the exposure conditions in the test procedures used to determine the resistance to water penetration of facades and façade elements. Furthermore, it has been shown that the technical specifications incorporated in the standards are sometimes too vague and can greatly affect the water penetration results. Therefore, we believe that the degree to test parameters defined for watertightness test standards impair the outcome of the test is an issue that requires further research on other types of façade systems and façade elements, to assist in the determination of the impact of such parameters on the performance class or performance level of the tested specimens.

\section{References}

1. D.A. Deress and C.R. Zimmer, Evaluating the water resistance of fenestration products, Paper presented at The RCI's 2009 Building Envelope Technology Symposium, San Diego, CA (2009, October 26-27).

2. Centre for Window and Cladding Technology, Technical Note No. 41 - Site testing for watertightness, University of Bath, UK: CWCT (2004).

3. American Society for Testing and Materials, Standard Guide for Evaluating Water Leakage of Building Walls, ASTM E2128, West Conshohocken, PA: ASTM International (2012).

4. M.Y.L. Chew, A modified on-site water chamber tester for masonry walls. Construction and Building Materials 15, 329-337 (2001). 
5. M. Arce et al. A new test standard to evaluate the watertightness of window-wall interfaces, Paper presented at the 14th International Conference on Durability of Building Materials and Components, Ghent, Belgium (2017).

6. N. Van den Bossche, Watertightness of building components. Principles, testing and design guidelines, Ph.D. Ghent, Belgium: University of Ghent (2013).

7. N. Sahal and M.A. Lacasse, Proposed method for calculating water penetration test parameters of wall assemblies as applied to Istanbul, Turkey, Building and Environment 43(7), 1250-1260 (2008).

8. European Committee for Standardization, Hygrothermal performance of building components and building elements. Determination of the resistance of external wall systems to driving rain under pulsating air pressure, EN 12865, Brussels, Belgium: CEN (2001).

9. Nordtest method, Windows, window-doors, external doors, facades: Pulsating air pressure test, NT BUILD 116, Espoo, Findland: Nordtest (1980).

10. Nordtest method, Roofs: Watertightness under pulsating air pressure, NT BUILD 421, Espoo, Findland: Nordtest (1993).

11. European Committee for Standardization, Hygrothermal performance of buildings resistance to wind-driven rain of roof coverings with discontinuously laid small elements - Test methods, FprEN 15601, Technical document final Draft, Brussels, Belgium: CEN (2009).

12. European Committee for Standardization, Windows and Doors - Watertightness - Test method, EN 1027, Brussels, Belgium: CEN (2000).

13. M.A. Lacasse et al., Towards development of a performance standard for assessing the effectiveness of window-wall interface details to manage rainwater intrusion, Journal of ASTM international 6(9), 1-28 (2009).

14. K.R. Hoigard and R.J. Kudder, The facts about hose testing, ASTM special technical publication 1314, 207-217 (1998). 